\title{
Fluctuación poblacional del insecto sogata, Tagosodes orizicolus empleando una trampa de luz y su relación con variables climáticas en Calabozo Estado Guárico, Venezuela

\author{
Population dynamics of planthopper insect, Tagosodes orizicolus performed using a light trap \\ and the ratio of the population with climatic factors in Calabozo, Guárico State, Venezuela
}

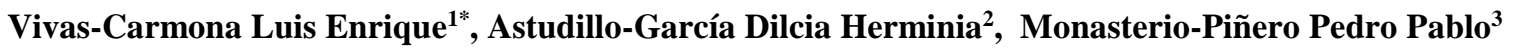

\begin{tabular}{|c|}
\hline Datos del Articulo \\
\hline $\begin{array}{l}{ }^{1} \text { Instituto Nacional de investigaciones } \\
\text { Agrícolas, INIA-Guárico, Calabozo Edo, } \\
\text { Guárico, Venezuela. Bancos De San } \\
\text { Pedro Km 27, Vía Apure. Calabozo estado } \\
\text { Guárico, Venezuela. Código postal } 2312 . \\
\text { Teléfono: 0246-238110. } \\
{ }^{2} \text { Instituto Nacional de Cooperación } \\
\text { Educativa Socialista, INCES. Avenida } \\
\text { Principal de Pinto Salinas, Frente a la } \\
\text { Cámara de Comercio, Calabozo Estado. } \\
\text { Guárico. Teléfono: 0246-8715592. } \\
\text { dilcita13@hotmail.com } \\
\text { 尚Centro de investigaciones Agrícolas de } \\
\text { Yaracuy, INIA-Yaracuy, Carretera Vía } \\
\text { aeropuerto Flores Boraure, San Felipe. } \\
\text { Estado Yaracuy. Telf. (+0254) 2311136/ } \\
\text { 2312265/2312692. } \\
\text { pmonasterio@inia.gov.ve }\end{array}$ \\
\hline *Dirección de contacto: \\
\hline $\begin{array}{l}\text { Luis Enrique Vivas-Carmona } \\
{ }^{1} \text { Instituto Nacional de investigaciones } \\
\text { Agrí́colas, INIA-Guárico, Calabozo Edo, } \\
\text { Guárico, Venezuela. Bancos De San } \\
\text { Pedro Km 27, Vía Apure. Calabozo estado } \\
\text { Guárico, Venezuela. Código postal } 2312 . \\
\text { Telf: 0246-238110. } \\
\text { E-mail: lvivas18@ yahoo.es } \\
\text { lvivas@inia.gob.ve }\end{array}$ \\
\hline Palabras clave: \\
\hline $\begin{array}{l}\text { Arroz, } \\
\text { Delphacidae, } \\
\text { Homóptera, } \\
\text { Oryza sativa, } \\
\text { variables climáticas. }\end{array}$ \\
\hline
\end{tabular}

J Selva Andina Biosph. 2017; 5(2):70-79.

\section{Historial del artículo.}

Recibido abril, 2017.

Devuelto septiembre 2017

Aceptado septiembre, 2017

Disponible en línea, noviembre 2017.

\begin{tabular}{|c|}
\hline $\begin{array}{c}\text { Editado por: } \\
\text { Selva Andina } \\
\text { Research Society }\end{array}$ \\
\hline Key words: \\
\hline $\begin{array}{l}\text { Climatic variables, } \\
\text { Delphacidae, } \\
\text { Homoptera, } \\
\text { Oryza sativa, } \\
\text { rice. }\end{array}$ \\
\hline
\end{tabular}

\section{Resumen}

Se realizaron estudios de la población del insecto sogata, Tagosodes orizicolus, Muir empleando una trampa de luz ubicada en el Centro de Investigaciones Agrícolas del INIA en Calabozo estado Guárico, en los Bancos de San Pedro, Venezuela ubicado a $73 \mathrm{msnm}$, entre los años 2000 a 2010. En un área clasificada como bosque seco tropical. Los objetivos de este trabajo fueron: Estudiar la fluctuación poblacional del insecto T. orizicolus, y la relación de la población con seis factores climáticos, información aportada por la sección de Climatología del mismo Centro. El cultivo de arroz en Calabozo, presenta a la especie T. orizicolus como la plaga más abundante e importante durante la época de verano, alcanzando picos poblacionales durante los meses de marzo y abril en los años de estudio. Así mismo, se encontró significación estadística entre las poblaciones del insecto con la temperatura media ( $\mathrm{p} \leq 0.0001)$, no resultando significativa la relación con las temperaturas mínima, máxima, humedad, evaporación y precipitación. Se describe la metodología y forma de evaluar al insecto con una trampa de luz en el arroz.

(C) 2017. Journal of the Selva Andina Biosph. Bolivia. Todos los derechos reservados.

\section{Abstract}

Population studies of planthopper insect, Tagosodes orizicolus Muir, were performed using a light trap located in the Centre of Agricultural Research INIA Calabozo in Bancos de San Pedro, Guárico state, Venezuela, located at 73 masl from 2000 to 2010. In an area classified as Dry Tropical Forest. The objectives of this study were to study the population dynamics of the insect $T$. orizicolus and the ratio of the population with six climatic factors, information provided by the Climatology section of the same center. Rice cultivation in Calabozo presents the species $T$. orizicolus the most abundant and important pest during the summer, reaching population peaks during the months of March and April in the years of study. Also, statistical significance between insect populations with the average temperature ( $\mathrm{p} \leq 0.0001$ ) was found, no significant relationship resulting with low temperatures, high, humidity, evaporation and precipitation. We also described the methodology and forms to evaluate the sogata insect using a light trap in rice. 


\section{Introducción}

Las pérdidas causadas por plagas representan una de las mayores limitantes en el incremento de la productividad del arroz, causando un aumento significativo de los costos de producción (LabrínSotomayor 2007). En el mundo, se estima que las plagas destruyen cerca del $35 \%$ de la producción de arroz, de las cuales $12 \%$ son causadas por patógenos (Pantoja-López et al, 1997, Vivas et al. 2002, 2010).

En el complejo de plagas que afectan al cultivo del arroz en Venezuela, ocupa un lugar importante, Tagosodes orizicolus Muir (1926), Homoptera de la familia Delphacidae, puesto que es el principal vector del virus de la hoja blanca (VHB) (Blanco \& González 1974, Blanco et al. 1973, Vivas 1997, 2008, Vivas \& Clavijo 2000).

Tradicionalmente, se han mencionado como plagas principales en el cultivo de arroz, al barredor Spodoptera frugiperda, la sogata $T$. orizicolus y las chinches vaneadoras, Oebalus insularis y O. ypsilongriseus. (Aponte 1990, Aponte et al. 1998, FONAIAP 1999, INIA Informe anual 2002, 2003, Vivas 1992, 1999, 2008, Vivas \& Clavijo 2000, Vivas et al. 2001, 2005, Vivas et al. 2010).

La Sogata, se considera una de las principales plagas que ataca el cultivo de arroz en Venezuela. (Vivas 2002). El insecto causa dos tipos de daño en la planta de arroz. El daño mecánico, que lo hace tanto al alimentarse como cuando coloca sus huevos, y el segundo, por ser el único insecto, capaz de transmitir VHB pudiendo dañar en casos extremos hasta el $100 \%$ de las plantas, cuando la variedad cultivada es susceptible al virus. El insecto puede trasmitir el virus en cualquiera de sus estados de desarrollo: ninfa o adulto (Vivas et al. 2002).
El virus es transmitido por el insecto sogata, de una manera persistente y la transmite la hembra (Transovárica) a su progenie (Gálvez 1968, Calvert \& Reyes 1999).

El VHB fue observado por primera vez en Colombia en 1935 (Morales \& Niessen 1983), siendo identificado su agente causal en 1983 por los mismos autores. En Venezuela, fue mencionada por primera vez por Malaguti (1956), Malaguti et al. (1956).

En la actualidad, la enfermedad se encuentra en todas las zonas arroceras tropicales del continente americano, en donde se han detectado epidemias cíclicas que se repiten cada diez a quince años provocando, como es de suponer, pérdidas importantes en producción. (Zeigler \& Morales 1990, Calvert \& Reyes 1999, Vivas \& Astudillo 2008).

Por otro lado, el VHB provoca un efecto deletéreo en insectos virulíferos, los cuales poseen una tasa de sobrevivencia menor que los insectos libres del virus. Se cree que el efecto que el virus causa en el insecto, junto con la lenta multiplicación de las plantas infestadas en el campo, son los responsables por la naturaleza cíclica de la enfermedad (PantojaLópez et al. 1997, Vivas 2006, Vivas et al. 2008).

Las epidemias son cíclicas y al presentarse, se han estimado pérdidas en rendimiento entre un $25 \%$ y $75 \%$. Los síntomas característicos de la hoja blanca en el arroz difieren según la variedad y la edad de la planta infectada. Los primeros síntomas sólo se observan en las hojas que emergen después de la inoculación del virus y consisten en áreas cloróticas o en lesiones típicas de un mosaico. Luego las áreas cloróticas, al hacerse más numerosas, se fusionan y forman rayas de color amarillo claro, paralelas a la nervadura central, desde el ápice hasta la vaina. Estos síntomas están acompañados de un secamien- 
to descendente de las hojas, siendo más notorio cuanto más joven sea la planta. Las plantas afectadas tienen menos macollas y presentan enanismo (CIAT 1985, Calvert et al. 1998, Vivas 1997, Vivas \& Astudillo 2008).

La información que se presenta forma parte de un proyecto con el fin de determinar la fluctuación poblacional de las plagas del arroz en Calabozo, estado Guárico, haciendo hincapié en T. orizicolus, una de las más importante especies de insectos que atacan las siembras en el Sistema de Riego Río Guárico (S.R.R.G) y así mismo, determinar su relación con las variables climáticas (Vivas 2008, Vivas \& Clavijo 2000, Vivas et al. 2001, 2005), Vivas 2006, Vivas et al 2010).

\section{Materiales y métodos}

El artefacto empleado como trampa de luz es una modificación al tipo Pensilvania desarrollado por Frost (1957), realizada por Doreste (1975), descrita en (Vivas 1997, 2008).

Consiste en un tubo de luz fluorescente (General Electric $20 \mathrm{w} / 55$ ), colocado en posición vertical, ocupando el centro de una jaula metálica cilíndrica de $50 \mathrm{~cm}$ de diámetro por $45 \mathrm{~cm}$ de altura, cubierta por una malla de alambre de celdas cuadrangulares de $2.0 \mathrm{~cm}$ de lado. El fondo del cilindro es un embudo de $40 \mathrm{~cm}$ de profundidad que termina en una boca de $5 \mathrm{~cm}$ de diámetro, a la cual va soldada una tapa de un recipiente plástico de $3.7 \mathrm{~L}$ de capacidad. Diariamente, se acopló a la tapa uno de los envases plásticos preparado con cianuro de potasio, actualmente se usa alcohol. La jaula se encontraba montada en una armazón metálica de manera que el borde inferior de la ventana de la trampa quedaba a $1.5 \mathrm{~m}$ sobre el nivel del suelo. Se empleó una sola trampa de luz. Cada día a las 4:00 p.m. se colocó el frasco cianurado y se encendió la luz de la lámpara que se encuentra muy cercana a la planta sede del Centro INIA Guárico, a $300 \mathrm{~m}$ del campo experimental de arroz, donde se hace mejoramiento genético y agronómico del cultivo en un área de 15 a 20 ha, La estación presenta un área total de 800 ha, en donde se desarrolla tanto la parte ganadera como la del rubro arroz. A las 7:30 a.m. del día siguiente, se apagó la luz, se tomó el recipiente y se extrajo el material atrapado durante la noche, luego se separaron los insectos sujetos a estudio. Se conservaron las especies de interés agronómico y algunos ejemplares, se enviaron al personal de Entomología del CENIAP (INIA) para identificación y preservación. (Vivas 1997, 2008).

La información obtenida por la trampa de luz (una sola trampa), se llevó por un período de 11 años (2001 a 2011) y se comparó con la información climática de: precipitación, temperatura media, máxima, mínima, humedad relativa y evaporación aportada por la sección de Climatología del Centro de Investigaciones Agrícolas del estado Guárico, ubicada en el kilómetro 28 de la carretera Nacional, vía Apure a $73 \mathrm{msnm}$, Longitud $67^{\circ} 30^{\prime}$ y Latitud $8^{\circ}$ 52 '.

Para el análisis estadístico, se utilizó el paquete estadístico InfoStat/Profesional, versión 1.1, 2004 y de estos, se empleó la prueba no paramétrica de Kruskal y Wallis en un diseño completamente aleatorizado para las variables en estudio (Población de individuos adultos de $T$. orizicolus) empleando como fuentes de dicho modelo: la época, el año, los meses del año y la interacción época por año. Así como, las variables climáticas citadas anteriormente.

\section{Resultados}

En la tabla 1, se presenta la variación de la población de $T$. orizicolus a lo largo del año para todo el 
período en el cual se realizaron las observaciones, en donde se determinó que la mayor incidencia de la población del insecto ocurrió en los meses secos, esto es, marzo y abril, para luego disminuir dichas poblaciones y hacerse casi insignificantes, desde el mes de julio a diciembre (época lluviosa).

Tabla 1 Fluctuación poblacional de $T$. orizicolus empleando una trampa de luz ubicada en la Estación Experimental del INIA - Guárico-Calabozo. Años: 2000 a 2010

\begin{tabular}{|c|c|c|c|c|c|c|c|c|c|c|c|c|}
\hline Mes/Año & Ene & Feb & Mar & Abr & May & Jun & Jul & Ago & Sep & Oct & Nov & Dic \\
\hline 2000 & 278 & 3569 & 289881 & 99106 & 9987 & 8978 & 567 & 212 & 98 & 49 & 36 & 26 \\
\hline 2001 & 186 & 1874 & 143101 & 81531 & 2461 & 3517 & 165 & 127 & 9 & 8 & 16 & 11 \\
\hline 2002 & 14 & 1058 & 212 & 1125 & 92 & 6 & 47 & 148 & 1229 & 137 & 41 & 6 \\
\hline 2003 & 11 & 550 & 3785 & 158 & 38 & 8 & 7 & 345 & 106 & 24 & 10 & 8 \\
\hline 2004 & 10 & 1227 & 8301 & 384 & 27 & 721 & 12 & 3 & 209 & 9 & 8 & 7 \\
\hline 2005 & 15 & 598 & 1537 & 732 & 43 & 36 & 12 & 53 & 962 & 84 & 25 & 2 \\
\hline 2006 & 4 & 160 & 758 & 207 & 92 & 23 & 26 & 18 & 11 & 52 & 10 & 8 \\
\hline 2007 & 7 & 98 & 8760 & 161 & 20 & 12 & 7 & 729 & 99 & 46 & 69 & 4 \\
\hline 2008 & 6 & 95 & 12503 & 11381 & 114 & 2 & 4 & 23 & 92 & 62 & 15 & 5 \\
\hline 2009 & 11 & 209 & 15483 & 8172 & 137 & 9 & 3 & 6 & 24 & 244 & 5 & 4 \\
\hline 2010 & 5 & 2400 & 792 & 247 & 80 & 33 & 4 & 36 & 64 & 15 & 33 & 17 \\
\hline Pro. & 49.7 & 1030.7 & 44084.8 & 18473.1 & 1190.1 & 1213.2 & 77.6 & 154.5 & 263.9 & 66.9 & 24.3 & 8.9 \\
\hline $\mathbf{S}$ & 92.5 & 1157.4 & 91482.1 & 35935.9 & 3004.6 & 2780.4 & 169.0 & 218.11 & 419.2 & 69.9 & 19.2 & 6.9 \\
\hline $\mathbf{S}^{2}$ & 8556 & 1339615 & $8.3 \mathrm{E}+09$ & $1.2 \mathrm{E}+09$ & $9.02 \mathrm{E}+06$ & $7.7 \mathrm{E}+06$ & $2.8 \mathrm{E}+04$ & $4.7 \mathrm{E}+04$ & $1.7 \mathrm{E}+04$ & 4892.65 & 369.25 & 48.69 \\
\hline
\end{tabular}

El análisis de la varianza de los datos para adultos de la población de T. orizicolus, empleando como fuente de variación del modelo: la época, detectó, diferencias altamente significativas para las medias correspondientes, $(\mathrm{p} \leq 0.0001)$.

Al comparar las épocas entre sí, se encontró que las poblaciones de $T$. orizicolus fueron más elevadas y estadísticamente diferentes en el periodo seco que en el período lluvioso, (tabla 2), mientras que al comparar los diferentes años, no se observó diferencias significativas a una probabilidad de $(\mathrm{p} \geq$ 0.1289).

Tabla 2 Comparación de las medias poblacionales de T. orizicolus para épocas del año

\begin{tabular}{cc}
\hline Época & Rango de medias \\
\hline seca & $11006.94 \mathrm{a}$ \\
Lluviosa & $99.29 \mathrm{~b}$ \\
\hline Medias seguidas por una misma letra común, \\
no son significativamente diferentes en el nivel de 5\%.
\end{tabular}

Tabla 3 Comparación de medias poblaciones del insecto $T$. orizicolus para los meses del año. Años 2000 a 2010

\begin{tabular}{lc}
\hline \multicolumn{1}{c}{ Meses del año } & Rangos de medias \\
\hline Marzo & $118.86 \mathrm{a}$ \\
Abril & $108.18 \mathrm{ab}$ \\
Febrero & $98.00 \mathrm{ab}$ \\
Mayo & $77.50 \mathrm{abc}$ \\
Septiembre & $73.64 \mathrm{cde}$ \\
Agosto & $64.18 \mathrm{cde}$ \\
Octubre & $59.91 \mathrm{def}$ \\
Junio & $55.45 \mathrm{def}$ \\
Noviembre & $43.14 \mathrm{efg}$ \\
Julio & $39.73 \mathrm{fg}$ \\
Enero & $38.00 \mathrm{fg}$ \\
Diciembre & $21.41 \mathrm{~g}$ \\
\hline Medias seguidas por una misma letra común, \\
no son significativamente diferentes en el nivel de 5\%
\end{tabular}

Así mismo, al comparar los meses del año entre sí, se consiguió diferencias altamente significativas entre ellos ( $\mathrm{p} \leq 0.0001)$, encontrándose que las poblaciones de $T$. orizicolus fueron más elevadas y estadísticamente diferentes en los meses de marzo, 
abril, (meses con las mayores poblaciones), febrero y mayo, cuando se comparó con los meses de diciembre, enero y julio, en estos últimos se presentaron las menores poblaciones (tabla 3 ).

La relación de las variables climáticas con las poblaciones del insecto, se presentan en las figuras $1 \mathrm{y}$ 2 , en donde, se puede apreciar que las mayores poblaciones del insecto, se presentaron, cuando la evaporación y las temperaturas máximas, medias y mínimas alcanzaron sus mayores valores y las menores poblaciones, cuando ocurren las mayores precipitaciones y humedad relativa.
Tabla 4 Comparación de las medias poblacionales del insecto $T$. orizicolus contra la temperatura media $\left({ }^{\circ} \mathrm{C}\right)$. Años 2000 a 2010

\begin{tabular}{ccc}
\hline Temperatura media (Trat) & \multicolumn{2}{c}{ Rango de medias } \\
\hline 29.3 & 127.00 & $\mathrm{a}$ \\
29.0 & 124.00 & $\mathrm{a}$ \\
28.9 & 123.00 & $\mathrm{a}$ \\
29.5 & 121.00 & $\mathrm{a}$ \\
30.8 & 120.00 & $\mathrm{a}$ \\
27.6 & 112.25 & $\mathrm{~b}$ \\
27.2 & 112.25 & $\mathrm{~b}$ \\
27.7 & 107.17 & $\mathrm{~b}$ \\
26.5 & 104.50 & $\mathrm{~b}$ \\
\hline
\end{tabular}

Valores seguidos de una misma letra dentro de la misma columna, no son significativamente diferentes al 5\%

Figura 1 Fluctuación poblacional del insecto "Sogata" contra la precipitación y evaporación en el periodo de estudio

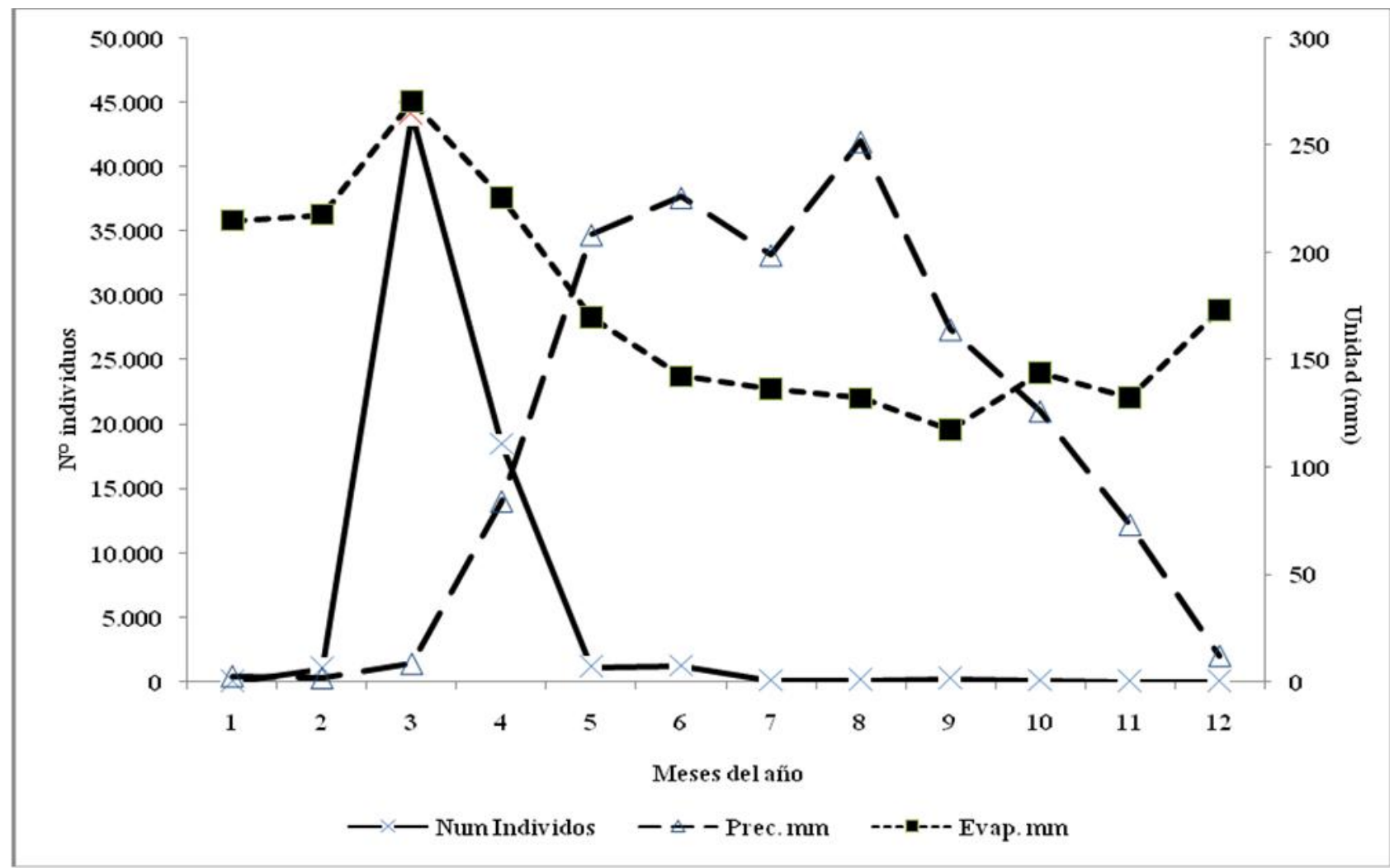


Figura 2 Fluctuación poblacional del insecto "Sogata" contra las temperaturas máxima, media, mínima y $\%$ humedad en el periodo de estudio

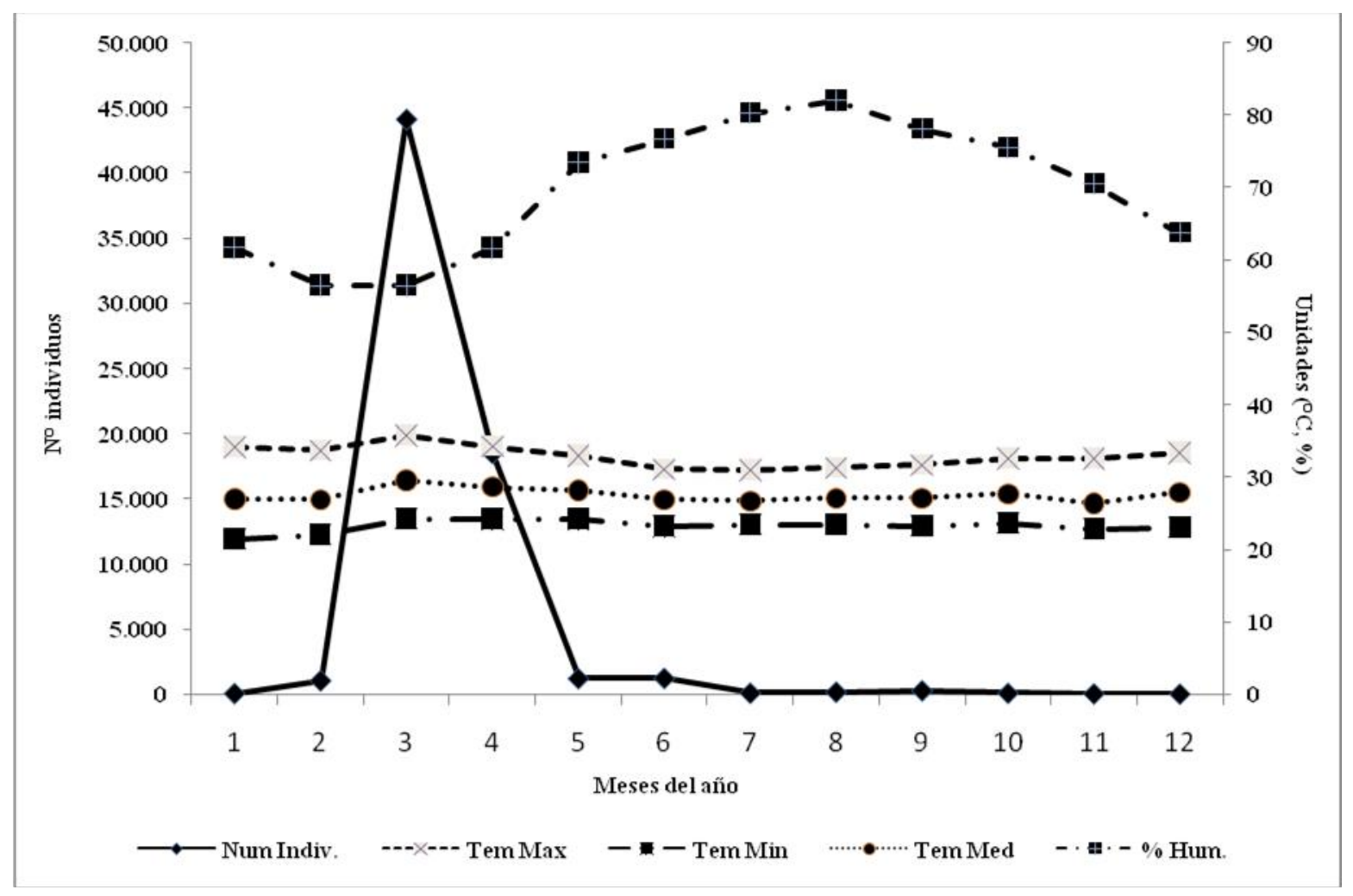

El análisis estadístico practicado a las capturas en trampa de luz con relación a los datos climáticos de los años en consideración, no dio los resultados de significación estadística esperada. A excepción de la temperatura media, la cual arrojo diferencias estadísticamente significativas a una probabilidad de ( $\mathrm{p} \leq 0.05$ ) (tabla 4). Observándose que las mayores poblaciones de la plaga coinciden con la época seca, cuando las temperaturas medias se sitúan entre los 28 y $29{ }^{\circ} \mathrm{C}$ y las más bajas poblaciones cuando la temperatura fluctuó entre 26 y $27{ }^{\circ} \mathrm{C}$, coincidiendo con la época de precipitación de la zona.

\section{Discusión}

La mayor abundancia poblacional del insecto se observó en los meses secos, marzo y abril, para luego disminuir en el periodo de lluvias de julio a diciembre. Estos resultados concuerdan con los de Blanco \& González 1974, Vivas 1997, en Calabozo, Gálvez (1967) en Colombia y Gómez et al. (1979), en Cuba quienes registran las mayores poblaciones del insecto durante el período de sequía y los niveles más bajos durante el período lluvioso. Por el contrario, Trujillo (1969) en Calabozo, encontró los picos poblacionales entre julio y agosto (período de lluvia), hasta septiembre a octubre, momento donde la población comienza a declinar. Igualmente, Gó- 
mez \& Meneses (1982), en otra zona arrocera en Cuba, mencionan que el período donde se registran las máximas poblaciones del insecto, está comprendido entre los meses de abril a noviembre y que coincide con las temperaturas más elevadas y las mayores precipitaciones. Así mismo, se observó que para todos los años bajo estudio durante la época seca, se presentan las mayores poblaciones del insecto sogata, cuando se compara con la época de lluvia, en donde ocurre el menor número de individuos del insecto. Esto, puede deberse a que durante la época seca, se presentan las condiciones climáticas más apropiadas para el desarrollo de las poblaciones de $T$. orizicolus, dicho período coincide con la mayor cantidad de área sembrada en la zona arrocera de Calabozo Estado Guárico y de la misma forma, con el lapso en el cual el agua de riego es aportada por el S.R.R.G. (Vivas 1997, 2008, Vivas \& Clavijo 2000).

La densidad poblacional de T. orizicolus, se encontró relacionada con la época y los meses del año, ya que la mayor densidad poblacional de adultos, fueron observados durante la época seca, en contraposición con las poblaciones del insecto en el periodo lluvioso, lo cual coincide con los datos obtenidos por Vivas (1997), Vivas \& Clavijo (2000) para el periodo 1987 a 1993.

Los máximos picos poblacionales del insecto, se presentaron durante los meses de marzo y abril y las menores poblaciones desde julio a diciembre, lo que igualmente, coincide con los datos de Vivas (1997), Vivas \& Clavijo (2000). De la misma manera, concuerda con los datos de campo, registrados por Gálvez 1967 en Colombia, Tascón \& García (1985), Gómez et al. (1977), Martínez et al. (1972) en Cuba y Vivas (1997), Vivas et al. (2009).

$\mathrm{Al}$ relacionar las poblaciones de la sogata del arroz con las variables climáticas. Las mayores poblaciones de la plaga coinciden con la época seca, cuando las temperaturas medias se sitúan entre los 28 y 29 ${ }^{\circ} \mathrm{C}$ y las más bajas poblaciones cuando la temperatura fluctuó entre 26 y $27{ }^{\circ} \mathrm{C}$, coincidiendo con la época de precipitación de la zona; datos estos que concuerdan con los reportados por Gálvez (1968) en Colombia y por Meneses et al. (2001), Red de mejoramiento de arroz para el Caribe, 1991 en Cuba, pero con picos poblacionales presentes entre los meses de abril a noviembre, los cuales se caracterizan por presentar las temperaturas más cálidas y así mismo manifiestan que entre los meses de diciembre hasta marzo disminuye la población del delfácido bajo la influencia de temperaturas más frescas (inferior a 25 $\left.{ }^{\circ} \mathrm{C}\right)$ y escasas precipitaciones y que se manifiestan contrarios a los encontrados por Gómez et al. (1979, 1982) en Cuba, los cuales mencionan que entre los meses de junio a septiembre, donde predominan altas temperaturas, se observó un notable descenso de la población del insecto, alcanzando los mayores picos poblacionales a menores temperaturas con un óptimo térmico de 25 a $26^{\circ} \mathrm{C}$.

En once años de estudio, las mayores poblaciones del insecto $T$. orizicolus se presentaron durante la época seca entre los meses de febrero a abril cuando las temperaturas medias se encuentran entre 28 a $29^{\circ} \mathrm{C}$ y con humedad relativa entre 56 y $61 \%$.

La densidad poblacional de la Sogata se encontró relacionada con la época del año, siendo significativamente superior en la época seca cuando se comparó con la época lluviosa.

Al comparar los meses del año, se encontró que las poblaciones de $T$. orizicolus fueron más elevadas y estadísticamente diferentes en los meses de marzo y abril cuando se compararon con el meses de julio a diciembre.

Solo se observó diferencias significativas entre las poblaciones del insecto Sogata con la temperatura media. 


\section{Conflictos de intereses}

No existe ningún conflicto de interés en el desarrollo de este trabajo de investigación.

\section{Agradecimientos}

A todo el personal del INIA-Guárico-Calabozo por su apoyo en el desarrollo de este trabajo de investigación.

\section{Literatura citada}

Aponte O, Vivas L, Escalona L, Castillo P. Manejo integrado de artrópodos plaga en arroz. Unidad de Aprendizaje para la Capacitación Tecnológica en la producción de arroz. FONAIAPFUNDARROZ-UCV-IUTEP. Acarigua, Venezu ela; 1998. p. 59.

Aponte O. Manejo integrado de plagas en arroz. Maracay, Venezuela. FONAIAP. Estación Experimental Portuguesa. Serie BN 13; 1990. p. 36.

Blanco ED, González H. Algunas medidas del combate de Sogata Sogatodes orizicola (Homoptera: Delphacidae) en arroz, en la zona de Calabozo. Boletín Informativo. Estación Experimental de Calabozo 1974;1(2):10-3.

Blanco ED, Luciani L, González H. Control químico de Sogata Sogatodes orizicola en el Sistema de Riego Río Guárico. Boletín de la Estación Experimental de Calabozo 1973;1(1):17-20.

Calvert GM, Karnik J, Mehler L, Beckman J, Morrissey B, Sievert J, et al. Acute pesticide poisoning among agricultural workers in the United States, 1998-2005. Am J Ind Med 2008;51 (12):883-98.

Calvert L, Reyes LA. Manejo del complejo "sogatavirus de la hoja blanca" en el cultivo del arroz.
Plegable. CO, CORPOICA - FEDEARROZ CIAT; 1999.

Centro Internacional de Agricultura Tropical (CIAT). Arroz: Investigación y producción. Editores: Tascón E y García D. CIAT-Colom bia; 1985. p. 696.

Doreste SE. Fluctuaciones de la población de algunas plagas en Cagua, estado de Aragua, Venezuela, según estudios realizados durante diez años con trampa de luz. Rev Fac Agron (Maracay) 1975;8(4):5-24.

Fondo Nacional de Investigaciones Agropecuarias. [FONAIAP]. Informe Anual de la Sección de Entomología. Estación Experimental Guárico. Calabozo, Guárico; 1999. p. 98.

Frost SW. The Pennsylvania insect ligt trap. J Econ Ent 1957;50(3):289-92.

Gálvez GE. Frecuencia de Sogata orizicola. Muir y Sogata cubana. Craawf en arroz y "Liendrepuerco", Echinocloa colonun en Colombia. Agricultura Trop 1967;18(6):385-90.

Galvez GE. Transmission studies of the hoja blanca virus with highly active, virus-free colonies of Sogatodes orizycola. Phytopathology 1968;58: 818-21.Gómez J, Meneses RC, Grillo M, Sarmiento GN. Relación entre el insecto Sogatodes orizicola, Muir (Homóptera: Delphacidae y la planta de arroz (Oryza sativa L.). Ctro Agr 1977; 4(3):85-91.

Gómez J, Meneses RC, Grillo M. Principales enemigos naturales de Sogatodes orizicola (Muir) (Homóptera: Delphacidae) en la zona arrocera de Sancti Spíritus. Cuba. Ctro Agr 1979;6(3):313.

Gómez J, Meneses RC. Dinámica de la población del insecto sogata Sogatodes orizicola (Muir) (Homóptera: Delphacidae) en la zona arrocera de Sancti spiritus, Cuba. Ctro Agr 1982;9(1):7-16. 
Infostat. InfoStat versión 1.1. Grupo InfoStat, FCA, Universidad Nacional de Córdoba, Argentina; 2004. p. 200.

Instituto Nacional de Investigaciones Agrícolas. Informe Anual de la Sección de Entomología. Estación Experimental Guárico. Calabozo, Guárico; 2002. p. 70.

Instituto Nacional de Investigaciones Agrícolas. Informe Anual de la Sección de Entomología. Estación Experimental Guárico. Calabozo, Guárico; 2003. p. 64.

Labrín-Sotomayor NY. Estudio de la resistencia en variedades de arroz (Oryza sativa L.) venezolanas al virus de la hoja blanca. [Tesis de Maestría]. Turrialba, Costa Rica; 2007. p. 84.

Malaguti G, Díaz H, Ángeles N. La "hoja blanca" del arroz. Agronomía Trop 1956;6(4):157-63.

Malaguti G. La "hoja blanca", extraña enfermedad del arroz en Venezuela. Agronomía Trop 1956; 6(3):141-5.

Martínez VR, González AM, Blanco N, Laffitte H. Enfermedades del arroz en la Provincia de Pinar del Río. (Cuba). Rev Agricultura 1972;(2):1521.

Meneses RC, Gutiérrez AY, García AR, Antigua GP, Gómez JS, Correa Victoria F, et al. Guía para el trabajo de campo en el manejo integrado de plagas del arroz. CIAT, IIA Cuba, FLAR. Publicación del Fondo Latinoamericano para arroz de riego (FLAR). Cuarta edición revisada y ampliada. Cali, Colombia; 2001. p. 76.

Morales JF, Niessen AI. Association of spiral filamentous virus like particles with rice hoja blanca. Phytopathology 1983;73(7):971-4.

Pantoja-López A, Fischer A, Correa-Victoria FJ, Sanint LR, Ramírez A, Tascón J, et al. Manejo integrado de plagas en Arroz: Manejo integrado de plagas; Artrópodos, enfermedades y ma- lezas. Calí, Colombia. Centro Internacional de Agricultura Trop. (Publicación CIAT N²92); 1997. p. 141.

Tascón ED, García D. (eds) Arroz: Investigación y Producción. CIAT, Cali, Colombia; 1985. p. 696.

Trujillo G. Investigaciones sobre las virosis "Hoja blanca" del arroz en Venezuela. IVIC-FONAI AP. (Informe); 1969. p. 89.

Vivas LE, Astudillo D, Poleo J. Monitoreo de Tagosodes orizicolus $\mathrm{M}$. e incidencia del virus de la hoja blanca "VHB" en el cultivo de arroz en Calabozo, estado Guárico, Venezuela Agro Trop 2009;59(4):457-67.

Vivas LE, Astudillo D. Enfermedades virales transmitidas por la familia Delhacidae con énfasis en el insecto sogata (Tagosodes orizicolus). Revista Digital INIA HOY. 2008; $\mathrm{N}^{\circ} 1$, enero-abril. [Citado 2015 Dic 07]. Disponible en: URL: http://www.inia.gov.ve/index.php? option=com_content\&task=view\&id=460.

Vivas LE, Cermeli M, Godoy F. Primera cita de Trigonotylus tenuis reuter, 1893 (Hemiptera, Miridae) causando daños en el cultivo del arroz (oryza sativa L.) en Venezuela. Entomotropica 2005;20(3):125-6.

Vivas LE, Clavijo S, González H. Distribución temporal y espacial y numero de muestras óptimo para la estimación de las poblaciones de sogata Tagosodes orizicolus, (Muir) 1926 (Homoptera: Delphacidae) en el cultivo de arroz, en Calabozo estado Guárico, Venezuela. Revista Científica "Investigación Agrícola". DANACPolar. 2001; [citado 2015 Aug 21] Disponible en: http://www.redpav-fpolar.info.ve/danac.

Vivas LE, Clavijo S. Fluctuación poblacional de $T a$ gosodes orizicolus (Muir) 1926 (Homoptera: Delphacidae) en el Sistema de Riego Río Guári- 
co, Calabozo estado Guárico, Venezuela. Bol Entomol Venez 2000;15(2):217-27.

Vivas LE, Lugo L, Acevedo M, Clavijo S. Determinación dela preferencia de Tagosodes orizicolus (Muir) 1926 (Homoptera: Delphacidae) sobre variedades de arroz, Calabozo Estado Guárico, Venezuela. Investigación Agrícola. 2002. 7:5. [Citado 2015 Jul 11]. Disponible en Internet. URL:http://www.redpavfpolar.

Vivas LE, Notz A, Astudillo D. luctuación poblacional del chinche vaneadora en parcelas de arroz, Calabozo, estado Guárico, Venezuela. Agro Trop 2010;60(1):61-73.

Vivas LE. Dinámica poblacional de la sogata del arroz, Tagosodes orizicolus (Muir) 1926 (Homoptera: Delphacidae) en el Guárico, Occidental. [Tesis de Maestría]. Facultad de Agronomía. Universidad Central de Venezuela. Maracay; 1997. p. 147.

Vivas LE. Fondo Nacional de Investigaciones Agropecuarias investiga insectos-plaga en el río Guárico. Arroz en las Américas. CIATColombia 1992;13(2):11-2.

Vivas LE. Manejo de insectos plagas en Calabozo. Boletín Resiembra. Concepto Milenium. Calabozo, Guárico. 1999;1(2):5.
Vivas LE. Manual de insectos plagas de arroz. INIA-SINGENTA. Maracay-Venezuela. Primera edición; 2002. p. 30.

Vivas LE. Muestreo secuencial del chinche vaneador del arroz, Oebalus insularis Stal (Hemiptera: Pentatomidae) sobre arroz (Oryza sativa L.) en Calabozo estado Guárico. [Tesis de Doctorado]. Facultad de Agronomía. Universidad Central de Venezuela. Maracay; 2008. p. 139.

Vivas LE. Plagas agrícolas de Venezuela: artrópodos y vertebrados: Saltahojas del arroz Tagosodes orizicolus Muir 1926 (en línea). SVE, Sociedad Venezolana de Entomología. 2006. [citado 2007 Jun 20] Disponible en: http://www.plagas-agricolas.info . ve/fichas/ficha. php?hospedero=58\&plaga=55.

Vivas LE. Plagas agrícolas de Venezuela: artrópodos y vertebrados: salta hojas del arroz Tagosodes orizicolus Muir 1926 (en línea). SVE, Sociedad Venezolana de Entomología. 2006. [citado 2016 Feb 06] Disponible en: http:// www.plagas-agricolas.info.ve/fichas/ ficha.php ?hospedero $=58 \&$ plaga $=55$.

Zeigler RS, Morales FJ. Genetic determination of replication of rice hoja blanca virus within its planthopper vector, Sogatodes orizicola. Phytopathology 1990; 80(6):559-66. 